\title{
BASHEVIS SINGER: TRADIÇÃO E MODERNIDADE
}

\author{
Eziel Belaparte Percino*
}

\section{Resumo}

Este artigo discorre sobre uma ambivalência presente nos contos de Bashevis Singer. Partindo do fato de que uma tensão entre tradição e modernidade, no contexto das produções literárias mais evidentemente marcadas pelo pano de fundo sociocultural judaico, está presente em muitos contistas desde o século XIX, embora sempre realizada de maneiras muito diferentes, e buscando o substrato teórico voltado à especificidade do conto judaico contemporâneo, são tomados aqui, especialmente, os contos de Bashevis Singer em que o schtetl, a aldeia judaica da Europa Oriental, aparece como cenário. A breve análise resulta em uma proposição bem definida: ao retomar paixões e fantasias poderosas, inspiradas pelo misticismo e pelo folclore judaicos, Bashevis Singer realiza, na verdade, o registro de uma oscilação incontornável entre dois mundos, dois polos, sob o signo da ambivalência, sem necessariamente emitir juízo.

Palavras-chave: Isaac Bashevis Singer, tradição, modernidade

\section{Abstract}

This article discusses ambivalence in Bashevis Singer's short stories. Based on the fact that the tension between tradition and modernity, in the context of literary productions clearly marked by the Jewish sociocultural background, is present in many short story writers since the nineteenth century, though it has been always handled in very different ways, and seeking the theoretical

* Doutorando em Teoria Literária e Literatura Comparada pela Faculdade de Filosofia, Letras

e Ciências Humanas da Universidade de São Paulo. <ezielpercino@gmail.com> 
background of the contemporary Jewish short story specifically, we took into consideration Bashevis Singer's short stories in which a schtetl, a Jewish's village in Eastern Europe, appears as scenario. The brief analysis results in a well-defined proposition: by retaking powerful passions and fantasies, inspired by the Jewish mysticism and folklore, Bashevis Singer is actually showing a compelling oscillation between two worlds, two poles, under the sign of ambivalence, without necessarily making any judgment.

Keywords: Isaac Bashevis Singer, tradition, modernity

Q ue espaço de experiência crítica se deve reservar para os contos de Isaac Bashevis Singer? Jacó Guinsburg afirma que é "[...] justamente nas formas concisas e sintéticas da composição contística ou novelística que a obra de Singer atinge seus momentos mais ricos e expressivos" (GUINSBURG, 1982, p. 60-1). A despeito de ter escrito alguns romances indispensáveis, Singer encontrou na modalidade do conto a melhor forma de colocar em cena, com agudeza e intensidade, um dos sentidos da identificação entre poeta e profeta: na tradição judaica, diz Singer, nunca houve diferença entre eles; desde a Bíblia, poetas e profetas convivem. Os contos, destituídos de feições vanguardistas, marcados pelo estilo econômico ou enxuto, sem rebuscamentos, estilo em que a linguagem, na singeleza de informar enquanto entretém, não busca tecer senão o ethos de vivências coletivas, realizadas às vezes com todos os matizes que caracterizam um modo "místico" de fantasia e que ganharam relevo midiático quando o escritor foi reconhecido pela Academia Sueca com o Prêmio Nobel, em 1978. Em linhas gerais, buscam motivo num universo sociocultural específico, amparados organicamente na "condição judaica" (no trânsito histórico do judeu da Europa Oriental, especialmente), mas geram, como que se abrindo ao leitor contemporâneo, um efeito de grande poder universalizante, comunicante em sua especificidade.

Morando em Nova York, Singer escrevia em iídiche, tornando imediatamente necessária uma tradução dos seus contos para o inglês. Na cerimônia de entrega do Prêmio Nobel de Literatura, ele explica o caso, em quatro blocos, da seguinte maneira: primeiro, acredita em fantasmas e gosta de escrever sobre eles. Nada combina melhor com um fantasma do que uma língua em extinção: os fantas- 
mas adoram o iídiche, afirma Singer, e todos eles falam esse idioma. Segundo, acredita em ressurreição. Os corpos de milhões de falantes do iídiche um dia se levantarão de seus túmulos, e sua primeira pergunta será: existe algum novo livro em iídiche para se ler? Terceiro, assim como o hebraico foi por anos considerado uma língua morta, mas de repente se tornou estranhamente vivo, o í́diche um dia também poderá ressuscitar. Quarto, o iídiche é uma língua em extinção, mas é a única que ele, Singer, conhece bem: é uma língua-mãe, e uma mãe nunca estará de fato morta. Essas explicações inusitadas, ou esses gracejos protocolares do escritor evidenciam, em todas as direções, uma espécie de humor que, no estilo, no tom, está muito presente em seus contos. Num sentido amplo, contudo, referemse talvez a um modo de resistência mais programático, embora não explícito: o uso do í́diche como uma recusa à absorção cultural americana.

Da escrita original, em iídiche, à interação desta língua no contexto das realizações literárias contemporâneas; da presença de Singer no âmbito do chamado "conto judaico" à particularidade deste no conjunto da literatura geral; da possível penetração histórica, da complexidade cultural e das texturas sociais supostamente imbricadas na ficção, engendradas ou tecidas às vezes pela síntese ficção-testemunho, às contradições do exílio e emigração e da própria história do povo judeu como referência emblemática (como ameaçado, perseguido), marcada pelo caminhar errante e muitas vezes por circunstâncias de violência - nos contos, nos romances, tem-se em Singer, pode-se dizer, uma experiência crítica que assim o experimente, os engenhos muito particulares de uma tensão, tanto nos efeitos dos domínios sobrenaturais que atravessam a ficção, nos quais se mergulha num imaginário judaico, quanto nos efeitos das narrativas de feição, por assim dizer, "realista": tradição e modernidade.

Essa tensão não é original nem rara: no sentido de abarcar as tradições judaicas e a modernidade ocidental, ela está presente em muitos contistas desde o século XIX. Sabe-se que o conto judaico moderno surgiu em paralelo ao processo de emancipação judaica e com o avanço das ideias do Iluminismo judaico (ou Haskalá); esse movimento, que se consolidou na Alemanha a partir do fim do século XVIII, mas cujas raízes se espalharam por toda a Diáspora ocidental, sustentou a defesa de reformas radicais na vida judaica, inspirado pelas ideias e pelos ideais da Ilustração europeia. Segundo Berta Waldman, foi exatamente o distanciamento da fé, durante o período da Haskalá, que deu 
início à "escritura da história", subtraindo, assim, a sustentação na sacralidade (WALDMAN, 2004, p. 16). Se até as primeiras décadas do século XIX os contos judaicos tinham um caráter eminentemente religioso, voltando-se para a interpretação de temas da tradição bíblico-talmúdica, o surgimento de um ideário secular e a sua difusão entre os judeus da Europa Oriental trouxeram a necessidade e o interesse por uma elaboração literária de temas ligados à realidade "profana", em que a passagem do mundo tradicional para a modernidade e o abandono de formas de vida ancoradas no legado medieval passaram a ocupar um lugar significativo. São dessa época as obras imersas no ideal da modernidade e a acidez crítica remetida à visão tradicionalista, à cartilha rabínica, à tradição - como, por exemplo, a primeira fase da obra de Mêndele Moher Sefarim, pseudônimo de Shalom Yaacov Abramovitch, escritor convencido da necessidade de uma reforma na vida judaica e da importância da difusão dos ideais iluministas.

É sempre pertinente se debruçar sobre este conflito específico entre o mundo da tradição judaica e o mundo moderno: a passagem de um mundo estribado em princípios espirituais, apoiado numa perspectiva transcendente da experiência humana, para um mundo secular em que os valores da tradição são relativizados; o choque entre os modos tradicionais de crenças e os modos de ser e de pensar típicos de uma sociedade laica; o deslocamento e o tornar-se deslocado num quadro de referências inteiramente outro; todas as fissuras e fraturas existenciais advindas de um processo sempre expressivo de desenraizamento; o antagonismo entre os valores de carga religiosa e os valores de carga profana. Diversas obras literárias colocaram em cena essas questões, sob os mais diferentes pontos de vista (KRAUSZ, 2012). Nisto, a tradição não raramente foi recortada por um olhar moderno, ganhando nuances somente negativas: tradição como impedimento, peso, retrocesso. Mas também a modernidade pôde ser recortada pelo olhar da tradição: modernidade como algo negativo, como algo insuficiente, como perda de valores essenciais.

Em Singer, deve-se dizer, tal território sempre instável tem uma feição peculiar. Produzidos no século XX, os contos de Singer, escritor que emigrou para Nova York em 1935, filho e neto de rabinos hassídicos, parecem articularse num alargamento desta mesma tópica, mas criando outros níveis de perspectivas e estabelecendo novos nexos entre o repertório da particularidade da 
tradição e o repertório do cosmopolitismo da modernidade. Ele retoma em muitos contos paixões e fantasias poderosas, ainda inspiradas pelo misticismo e pelo folclore judaicos, para agora deixar evidente, por formas renovadas, não uma crítica imediatamente escancarada ou empenhada contra a tradição, mas exatamente uma ambiguidade, como um caso não resolvido. Nele, há o registro de uma oscilação incontornável entre dois mundos, sob o signo da ambivalência, sem necessariamente emitir juízo. Não há satisfação com uma crítica à tradição realizada apenas por um olhar moderno, assim como não há satisfação com uma crítica à modernidade realizada apenas por um olhar da tradição: Singer movimenta-se, isento, entre dois polos (BUCHEN, 1968; ALEXANDER, 1990; CAVAGLION, 2005).

Giuseppe Pontiggia, em "Il viaggiatore nei due mondi", diz que a ficção de Singer é "[...] oscilante entre predestinação e incerteza, ceticismo e fé, modernidade agnóstica e religiosidade popular” (PONTIGGIA, 2005, p. XII). Tomese como objeto a antologia The Collected Stories of Isaac Bashevis Singer, reunião muito representativa de suas narrativas breves: tradição e modernidade têm uma presença importante e, em quase todos os contos, são o leitmotiv da construção ficcional, como misto de invenção e memória. O mergulho recorrente no schtetl, a aldeia judaica da Europa Oriental, jamais tende, assim, diretamente, a uma crítica da tradição: trata-se muito mais de uma retomada criativa, regada quase sempre por aquele delicioso humor singeriano, dos contornos de um "mundo morto" que insiste em viver. Mesmo nos contos mais caricaturescos, em que os elementos místicos são impressos na própria tessitura do texto literário, tomados enquanto evidentes ingenuidades ou graves alienações, não há nenhuma contraposição à tradição. Singer produz, assim, a experiência esquizofrênica de tomar, ao mesmo tempo, numa determinada situação, sem apologia, valores outrora vistos apenas como opostos: os da tradição e os da modernidade.

Ao contrário do que é possível observar nas literaturas de outros autores contemporâneos a Singer, a vida coletiva judaica permanece pulsante e atuante, da recuperação do repertório espiritualista no imaginário hassídico às dúvidas e inquietações sobre a amplitude da vida moderna, envolvendo tanto a figura do judeu nas ruelas das cidadezinhas judaico-polonesas quanto a do judeu na América, como no início do conto O cabalista de East Broadway: 
Como acontece tantas vezes em Nova York, o bairro mudou. As sinagogas viraram igrejas, as yeshivas, restaurantes ou estacionamentos. Aqui e ali ainda se vê um asilo judeu para velhos, uma loja vendendo livros hebraicos, um ponto de encontro para landsleit de alguma aldeia da Rússia ou da Hungria. (SINGER, 2004, p. 446)

Cá, lá, tradição e modernidade se fazem figurar, entrecortadas por um modo ambíguo, oscilante; e o peculiar é que os contos se valem, para alcançar tal efeito, de um narrador de tipo "externo", numa enunciação quase impessoal, embora muitas vezes como narrador autodiegético.

Para os que atravessaram o Atlântico, o "novo" substitui o "antigo", mas não sem reintroduzi-lo continuamente, como traços memoriais, ora com desencanto, ora com ceticismo, ora com nostalgia. Os judeus não são exatamente o povo da história: são o povo da memória, afirma Jacques Le Goff (1997, p. 24). Por isso, o schtetl é o cenário preferencial de Singer, recordado mesmo quando os protagonistas estão entre as ruas da grande Nova York. Das vielas, das casinhas, do pequeno-grande-mundo do schtetl, salta, na ficção de Singer, de maneira decisiva, esta espécie de esquizofrenia vital, assentada na tensão entre tradição e modernidade. Ainda mesmo nos chamados contos de caráter "fantástico", como O cavalheiro da Cracóvia, a projeção do sobrenatural ocorre, como matéria para a prática da leitura contemporânea, vacilando, afrouxada - sim, numa duplicidade de referências, entre o imaginário popular-tradicional e as perspectivas de leituras modernas ali previstas.

Guinsburg, numa nota em $O$ conto ídiche, diz que a obra de Singer é

[...] uma busca dos elementos patológicos e anormais da vida religiosa judaica", e enfatiza que "Bashevis é um analista das paixões e dúvidas que atormentam espíritos profundamente religiosos. (GUINSBURG, 1966, p. 323-4) 
Entenda-se, entretanto, que a vida religiosa, tomada, assim, de maneira direta e exclusiva, não é o fulcro desta ficção: os contos de Singer apontam para uma problemática vital e mais efetiva, de feição histórica e sociocultural, muito complexa, tecida neles a partir de uma inegável ambivalência entre tradição e modernidade. No humor da "aproximação" ao tradicional, que é penetrado pela lente hiperbólica de um narrador, está a capacidade de expressar cômica e criticamente a especificidade de uma cultura mística, mas não é esta a sua única face nem é este o seu mote fundamental. Ao retratar ofícios (sapateiros, alfaiates, lenhadores, rabinos), bem como os ingredientes religiosos que os caracterizam, Singer desenha, é claro, uma especificidade: desencadeia, ao nível do judeu moderno e de sua problemática, um modo de experimentar essa especificidade sob uma luz laica, como Guinsburg mesmo afirma, no mesmo texto, ao melhorar a sua formulação: “[...] ou melhor, poder-se-ia dizer que projeta na tessitura intrincada do sentimento piedoso uma luz oblíqua de visão moderna e laica, dividindo-o e tornando-o grotesco por esta "re-velação"" (1966, p. 324). Por outro lado, porém, deve-se dizer, os valores da vida moderna não deixam de ser igualmente atravessados pela força da tradição - assim, talvez, como uma busca dos elementos patológicos e anormais da vida moderna, como uma análise das paixões e dúvidas que atormentam também a modernidade. O próprio uso do í́diche é, em Singer, uma forma particular de resistência à modernidade (SANDERS, 1989; LEE, 1987). Faz-se, assim, um movimento simultâneo e paradoxal: tradição pela modernidade e modernidade pela tradição: um caso não resolvido, dado semelhantemente como experiência ainda mista e neutra.

As histórias que envolvem os moradores do schtetl estão repletas de eventos miraculosos, maravilhosos e inacreditáveis - e, exatamente aí, de crenças, práticas místicas, no modus faciendi de seus elementos, mesmo quando estes estão carregados de licenças ficcionais excessivamente fantasistas. No exagero das nuanças ou na exatidão dos substratos históricos, Singer monta uma arquitetura ficcional característica - assim, permeada por noções fervorosas, ou mesmo supersticiosas, sempre oriundas de um contexto cultural recuperado, como até mesmo neste trecho mínimo de Os pequenos sapateiros: 
No Rosh Hashanah os judeus de Frampol realizaram suas cerimônias na floresta, com Abba conduzindo a prece mais solene das Dezoito Bênçãos, porque era o único que tinha uma estola de oração [...] Abba sentiu que tinha se transformado em seu próprio tataravô. (SINGER, 2004, p. 72)

Nos contos mais emblemáticos, a mística judaica e a noção vertical de religiosidade estão sempre presentes, firmadas sobre categorias evidentemente carismáticas ou pietistas, de onde às vezes emergem fenômenos psíquicos, clarividências, premonições, feitiços. As histórias têm como matéria fundamental uma designação muito precisa - desta maneira, como se pode afirmar nos termos de Irving Howe: "[...] o mundo dos judeus europeus do Leste era colorido por todo tipo de emoções religiosas" (HOWE, 1976, p. 9). Sobretudo, sugerem uma definição de bases problemáticas, tecidas a partir de tópicas, por assim dizer, não convencionais, vertidas do ideário hassídico, em que figura Deus, mas também demônios singulares e crenças medonhas.

Nesse mundo "intoxicado de Deus" (GUINSBURG, 1996, p. 60), as pessoas têm uma intimidade dialógica com Deus. Diz Howe, comentando a cultura iídiche, em World of our fathers: " [...] era uma cultura da fala, e Deus um Deus que falava" (HOWE, 1976, p. 11). No ideário hassídico, tal projeção dialógica está presente em todas as coisas, em todas as esferas da vida, nos detalhes do cotidiano, mesmo no mínimo âmbito das experiências humanas, encontrando-se as leis divinas ao alcance de todos, como é possível ver muitas vezes nos contos singerianos - e não apenas ao alcance de eruditos, ou de uma elite culta, ou de alguns privilegiados (GUINSBURG; FALBEL, 1971). Promulgando essa íntima vinculação entre Deus e os seres humanos, os ensinamentos são simples e efetivos, abolindo muitas vezes as diferenças entre espaços ou tempos sagrados e profanos, entre ações ou palavras sagradas e profanas. Neste sentido, há em Singer não exatamente um ardor obscurantista de beatos ignorantes, explorados em sua crendice por curandeiros e taumaturgos, nem exatamente um protesto das massas asfixiadas pela ortodoxia rabínica ou pela opressão econômica e política do meio gentílico, mas, sobretudo, uma proje- 
ção ambivalente, assim, dos "tesouros ocultos" de seres humanos específicos, num determinado contexto.

Ludwig Feuerbach escreveu um dia que a religião, em todas as suas formas, é o solene desvelar dos tesouros ocultos do homem, a revelação dos seus pensamentos íntimos, a confissão pública dos seus segredos de amor, que "[...] a consciência de Deus é a consciência que o homem tem de si mesmo, o conhecimento de Deus o conhecimento que o homem tem de si mesmo" (FEUERBACH, 1997, p. 55). Pode-se por aí conjecturar: o problema de compreender a realidade no schtetl, tão intimamente penetrado pelas narrativas de Singer, é semelhante à questão desses "tesouros", no sentido mais amplo. Assim, as personagens de Singer estão longe de serem meramente grotescas: como diz Moacyr Scliar, "[...] são pessoas à mercê de paixões e fantasias poderosas" (SCLIAR, 2004, p. 10). No que se referem à mística e à contundência desta no contexto de uma leitura contemporânea, seus signos não apontam para um significado solene (tradição ou modernidade): sugerem uma teia complexa de significações simultâneas e sempre deslizantes (tradição e modernidade): são, por assim dizer, "símbolos de tesouros", signos primários continuamente transportados a signos secundários, flutuantes; referem-se ao ser humano, como fenômeno histórico-social, e hospedam, ao mesmo tempo, "seres" de outra espécie, transpassáveis, transportáveis, metamorfoseáveis. Novamente, é claro, o "olhar tradicional" e o "olhar moderno" se entrecruzam.

Nas narrativas de Singer, os costumes e o imaginário religioso são postos em evidência, mas o humor judaico tempera: é um tipo de humor que ri com um olho e chora com o outro: humor, assim, talvez, impregnado de amargura. Scliar também o diz: "[...] é um humor peculiar, contido, melancólico, filosófico; não é humor para gargalhadas, antes para um sorriso" (SCLIAR, 2004, p. 9). No coração deste tipo de humor, a impressão de que uma zona mais contundente e mais problemática emerge solicita sempre novos tipos de experiências. No diabo ou demônio que aparece em muitos contos está o desmascaramento revel do imaginário e o raio $\mathrm{x}$ de determinada cosmovisão, mas também a "graça" do Ser difuso. Em $O$ invisivel, por exemplo, ele é o narrador que comicamente se apresenta: 


\begin{abstract}
Dizem que eu, o Mau Espírito, depois de descer à terra para induzir as pessoas ao pecado, subo ao Céu para acusá-las. Na verdade, sou também aquele que dá o primeiro empurrão no pecador, mas faço isso de um jeito tão esperto que o pecado parece um ato de virtude; assim, outros infiéis, não podendo aprender pelo exemplo, continuam a cair no abismo. (SINGER, 2004, p. 79)
\end{abstract}

As coisas se organizam a partir das imagens vivas da fantasia designada e das emoções inerentes ao discurso: elementos ligados menos pelo princípio do discurso lógico do que do discurso fantasista. Um humor delicado está na base da composição.

Já no conto Taibele e seu demônio, o "demônio" é um espertalhão, cheio de truques libidinosos; na verdade, um homem que se faz passar por demônio: "Não grite, Taibele. Se gritar, destruo você. Sou o demônio Hurmizah, que domina a escuridão, a chuva, o granizo, o trovão e as feras selvagens" (SINGER, 2004, p. 163). Não deixa de ser algo temperado pelo humor, mas agora um humor ocupado pelo medo da morte: humorte. Tirando proveito do medo e da ingenuidade, o "demônio" obriga Taibele a lhe conceder favores sexuais, e passa a encontrá-la periodicamente. Nesses encontros, ele conta histórias mirabolantes sobre a sua vida, seus relacionamentos com outros demônios, suas peraltices pelo céu e pelo inferno, construindo, assim, uma espécie de demonologia imaginária. $\mathrm{O}$ medo e a mística são os ingredientes de um envolvente jogo de sedução entre o "demônio" e a pequena loira de olhos azuis, Taibele:

No começo, ela teve medo que seu visitante noturno pudesse lhe fazer mal [...] Mas Hurmizah não a chicoteou, nem beliscou, nem cuspiu em cima dela. Ao contrário, ele a acariciava, sussurrava carinhos, fazia trocadilhos e rimas para ela. (SINGER, 2004, p. 165)h 
No caráter paradoxal do "demônio" e nas reações também paradoxais de Taibele, Singer realiza certa desmoralização da ingenuidade e, ao mesmo tempo, penetrando nas faces ocultas dessas personagens, colocando-as na vitrine, revela a presença de desejos insatisfeitos, impulsos inconfessos, desvios reprimidos - espécie de desconstrução refinada.

Singer trabalha com a tradição judaica a partir de um repertório de vicissitudes, experiências e projeções calcadas no imaginário popular. Tal imaginário popular, sob a forma de um estranhamento, é o recurso que os contos reclamam para seduzir à ambiguidade todas as perspectivas: como que sugerindo nexos, retoma-as atadas. Nesse sentido, a ambiguidade entre tradição judaica e modernidade parece antever uma espécie de leitura que, seduzida também a uma ambiguidade entre antigo e novo, pode mirar um mundo otimamente familiar e, a um só tempo, absolutamente estranho, como aponta um intérprete da obra de Singer, Joseph Landis: "[...] il mondo di Singer ci sembra familiare, ma è assai strano" (LANDIS, 1985, p. 59). Esse mundo familiar e estranho, habitado por rabinos, místicos, endemoninhados e almas penadas (dibbuk), conecta-se às histórias que o próprio autor ouvia em sua infância, à atmosfera de intensa religiosidade em que Singer foi educado, do que certamente vêm os elementos predominantes de seu estilo e o estímulo de rever um "mundo morto", o das pequenas comunidades judias nas aldeias polonesas, sem emitir um parecer panfletário. Singer conhecia o folclore e as máximas de um modo de ver e pensar: parece então utilizar esse "conhecimento" para trabalhar, no âmbito da ficção, uma ambiguidade entre tradição e modernidade. A grande permeabilidade dos contos em relação ao referente concretamente qualificado, tanto do ponto de vista histórico quanto geográfico, solicita, de qualquer forma, um espaço de experiência crítica que, a partir dos procedimentos de linguagem, do modo fantasista, do repertório ficcional, consiga dar conta das associações manifestas: afinal, o panorama existencial da ficção de Singer não é mera fantasia, mas signo de um mundo que realmente existiu; não são, deste modo, simples narrativas, mas objetos estéticos condicionados pela cultura judaica, no "entre mundos" da tradição e da modernidade; não como documentos ou reflexos da realidade, mas como experimentações pulsantes, advindas de uma oscilação capital. 


\section{Referências}

ALEXANDER, Edward. Isaac Bashevis Singer: a study of the short fiction. Boston: Twayne Publishers, 1990.

BUCHEN, Irving. Isaac Bashevis Singer and the Eternal Past. New York: New York University Press, 1968.

CAVAGLION, Alberto. “Introduzione”. In: Racconti, Isaac Bashevis Singer. Milano: Arnoldo Mondadori Editore S.p.A., 2005.

FEUERBACH, Ludwig. A essência do cristianismo. Campinas: Papirus, 1997.

GUINSBURG, Jacó. "Um escritor de muitos demônios”. In: O Golem. São Paulo: Perspectiva, 1982.

. Aventuras de uma lingua errante: ensaios de literatura e teatro ídiche. São Paulo: Perspectiva, 1996.

. (org.). O conto ídiche. São Paulo: Editora Perspectiva, 1966.

GUINSBURG, Jacó; FALBEL, Nachman (orgs.). Aspectos do Hassidismo. São Paulo: B'nai B'rith, 1971.

HOWE, Irving. World of our fathers. New York: Simon \& Schuster, 1976.

KRAUSZ, Luís Sérgio. Passagens: literatura judaico-alemã entre gueto e metrópole. São Paulo: Edusp, 2012.

LANDIS, Joseph. I. B. Singer: alone in the Forest. Yiddish VI. n. 2-3, p. 59, 1985.

LE GOFF, Jacques. Memória e História. Portugal: Imprensa Nacional - Casa da Moeda, 1997.

LEE, Grace. From exile to redemption: the fiction of Isaac Bashevis Singer. Carbondale: Southern Illinois University Press, 1987.

PONTIGGIA, Giuseppe. "Il viaggiatore nei due mondi". In: Racconti, Isaac Bashevis Singer. Milano: Arnoldo Mondadori Editore S.p.A., 2005.

SANDERS, Ronald. The americanization of Isaac B. Singer. New York: Syracuse University Press, 1989.

SCLIAR, Moacyr. "O mundo de Singer" (introdução). In: 47 contos de Isaac Bashevis Singer. São Paulo: Companhia das Letras, 2004.

SINGER, Isaac Bashevis. 47 contos de Isaac Bashevis Singer. São Paulo: Companhia das Letras, 2004.

. The Collected Stories of Isaac Bashevis Singer. New York: Farrar, Straus and Giroux, 1982.

WALDMAN, Berta. Linhas de força: escritos sobre literatura hebraica. São Paulo: Humanitas, 2004. 